\title{
SYMPOSIUM
}

\section{Neuronal fiber pathway abnormalities in autism: An initial MRI diffusion tensor tracking study of hippocampo-fusiform and amygdalo-fusiform pathways}

\author{
THOMAS E. CONTURO,${ }^{1}$ DIANE L. WILLIAMS,${ }^{2}$ CHARLES D. SMITH, ${ }^{3}$ EREN GULTEPE, ${ }^{1}$ \\ ERBIL AKBUDAK, ${ }^{1}$ and NANCY J. MINSHEW ${ }^{4}$ \\ ${ }^{1}$ Mallinckrodt Institute of Radiology, Washington University School of Medicine, St. Louis, Missouri \\ ${ }^{2}$ Department of Speech-Language Pathology, Duquesne University, Pittsburgh, Pennsylvania \\ ${ }^{3}$ Department of Neurology, University of Kentucky, Lexington, Kentucky \\ ${ }^{4}$ Departments of Psychiatry and Neurology, University of Pittsburgh School of Medicine, Pittsburgh, Pennsylvania \\ (Received February 1, 2008; Final Revision August 4, 2008; Accepted August 5, 2008)
}

\begin{abstract}
MRI diffusion-tensor tracking (DTT) was performed in 17 high-functioning adolescents/adults with autism and 17 pairwise-matched controls. White matter pathways involved in face processing were examined due to the relevance of face perception to the social symptoms of autism, and due to known behavioral and functional imaging findings in autism. The hippocampo-fusiform (HF) and amygdalo-fusiform (AF) pathways had normal size and shape but abnormal microstructure in the autism group. The right HF had reduced across-fiber diffusivity (D-min) compared with controls, opposite to the whole-brain effect of increased D-min. In contrast, left HF, right AF, and left AF had increased D-min and increased along-fiber diffusivity (D-max), more consistent with the whole-brain effect. There was a general loss of lateralization compared with controls. The right HF D-min was markedly low in the autism subgroup with lower Benton face recognition scores, compared with the lower-Benton control subgroup, and compared with the higher-Benton autism subgroup. Similar behavioral relationships were found for performance IQ. Such results suggest an early functionally-significant pathological process in right HF consistent with small-diameter axons (with correspondingly slower neural transmission) and/or higher packing density. In left $\mathrm{AF}$ and $\mathrm{HF}$, changes were interpreted as secondary, possibly reflecting axonal loss and/or decreased myelination. (JINS, 2008, 14, 933-946.)
\end{abstract}

Keywords: Autism, Diffusion tensor MRI, White matter fiber tracking, Fusiform face area, Amygdala, Hippocampus, Face recognition, DTT, White matter pathways

\section{INTRODUCTION}

Many advances have been made in the past several decades in characterizing the unique behavioral and cognitive features of autism and, more recently, the neurobiological basis of this disorder. The neurobiologic findings have led to the current understanding of autism as a disorder of neural systems and connectivity (e.g., Belmonte et al., 2004; Just et al.,

Correspondence and reprint requests to: Thomas E. Conturo, Mallinckrodt Institute of Radiology, Washington University School of Medicine, 4525 Scott Avenue, Campus Box 8225, St. Louis, MO 63110. E-mail: tconturo@wustl.edu
2004; Minshew, 1996; Minshew \& Williams, 2007), mainly affecting local intra-cortical connections, cortico-cortical connections, and cortico-subcortical connections. This model of autism evolved from converging evidence that suggested both gray and white matter abnormalities in autism. Some of the first evidence came from studies that demonstrated that most, though not all, children with autism exhibited an acceleration in head growth by age 12 months that was shown by later structural MRI studies to result from increased volume of cortical gray and intra-cerebral white matter (Aylward et al., 2002; Courchesne et al., 2001; Hazlett et al., 2005; Lainhart, 2006). The increase in intra-cerebral white 
matter volume has been shown to predominantly involve the outer radiate white matter (cortico-cortical connections) (Herbert et al., 2004). A landmark histopathologic study contributed further to the emerging picture by reporting increased horizontal density of the vertically oriented columns of cortical cells (minicolumns) (Casanova et al., 2002). Thus, the increase in cortical gray matter was linked to the increase in white matter by the increase in white matter projections necessary to maintain the connectivity of the increased number of cortical cells (Casanova et al., 2002, 2003, 2006).

These emerging anatomic findings suggesting disturbances in brain connectivity in autism were substantiated and elaborated by the functional magnetic resonance imaging (fMRI) studies of Just and colleagues who reported a reduction in functional correlation among key brain regions activated during various executive, social, and language tasks (Just et al., 2004, 2007; Kana et al., 2006, 2007; Koshino et al., 2005; Luna et al., 2002; Mason et al., 2008). These findings indicate that the brain in autism is broadly characterized by an under-connectivity at the system level. Functional measures of the synchronization of activation between different cortical regions are thought to reflect the performance of the white matter connecting these regions, suggesting the importance of specifically examining white matter pathways in autism.

A continuing area of interest, related to the significant social impairment in autism, has been the decreased ability to recognize and remember faces and to identify emotion in faces (Adolphs et al., 2001; Celani et al., 1999; Dawson et al., 2002, 2004; Gepner et al., 1996; Klin et al., 1999). Therefore, numerous fMRI studies of face processing have been completed in autism. Many fMRI studies have reported a reduction in fusiform face area activation and a possible reliance on object processing areas in response to face stimuli in individuals with autism (Baron-Cohen et al., 1999; Critchley et al., 2000; Grelotti et al., 2005; Hubl et al., 2003; Pierce et al., 2001; Schultz, 2005; Schultz et al., 2000) with object processing being less affected in autism (Humphreys et al., 2008). In other fMRI studies of autism, fusiform activation was found in response to faces (Hadjikhani et al., 2004, 2007; Pierce et al., 2004), or related to time spent fixating on the eyes (Dalton et al., 2005). Such variability of results has been interpreted as suggesting anomalies of networks rather than of a single brain area (Hadjikhani et al., 2004). Additional fMRI studies have reported reduced functional correlations between the fMRI signal measured from the fusiform face area and other relevant activated brain areas in various tasks in autism (Kleinhans et al., 2008; Koshino et al., 2008). Taken together, these results suggest that face-processing networks involving the fusiform area are implicated in autism, but the nature of the neurobiological abnormality is not yet understood.

The fusiform area is functionally related to amygdala and hippocampus, two other structures that have been studied with respect to autism. Several fMRI studies have reported abnormal amygdala activation in autism during face and emotion processing (Ashwin et al., 2007; BaronCohen et al., 1999; Critchley et al., 2000; Dalton et al., 2005; Wang et al., 2004). Hypoactivation of the amygdala during face processing has been found even when no significant difference occurred in activation of the fusiform (Hadjikhani et al., 2007). One fMRI study (Pierce et al., 2001) reported abnormal activation of the fusiform face area and anatomical abnormalities in the amygdala in the same adult subject group with autism.

Studies of very young children with autism (age 2-4 years) demonstrated that the amygdala and hippocampus were also involved in the early brain overgrowth process (Sparks et al., 2002), with enlargement associated with social/communication symptoms (Munson et al., 2006). Cross-sectional studies of older children, adolescents and young adults had variable findings, typically showing normal or decreased amygdala and/or hippocampal volume (Aylward et al., 1999; Herbert et al., 2003; Nacewicz et al., 2006; Nicolson et al., 2006; Pierce et al., 2001; Piven et al., 1998; Schumann et al., 2004). However, studies also showed enlargement of the hippocampi persisting through adolescence (Palmen et al., 2006; Schumann et al., 2004), disproportionally affecting right hippocampus (Schumann et al., 2004). Another study found a subtle shape abnormality of the right hippocampus in children with autism (Nicolson et al., 2006). Overall, the volumetric studies of amygdala/ hippocampus suggest early overgrowth followed by normalization of the amygdalar volumes in middle childhood with normalization or persistence of the hippocampal enlargement. The normalization of total brain volume and individual structures after middle childhood occurs in a context of continued behavioral deficits and differences in functional brain measures, suggesting abnormalities at the microstructural level in autism.

Diffusion-tensor MRI (DT-MRI) provides a tool for defining and characterizing white matter pathways and the microstructural level in vivo, thus providing an opportunity for defining the basis for functional impairments in pathways of central importance to the pathophysiology of autism. DT-MRI produces quantitative images of the microscopic mobility or diffusion of water in tissues. Measurements of the degree to which diffusion is direction dependent (diffusion anisotropy) are sensitive to microstructural features of white matter (Pierpaoli et al., 1996; Shimony et al., 1999). The related technique of diffusion-tensor tracking (DTT) can be used to trace neuronal fiber pathways (Conturo et al., 1999; Mori et al., 1999) and test for altered connectivity between brain regions. DTT can be combined with DT-MRI to measure tensor parameters (e.g., anisotropy) within the exact data space of a pathway, to evaluate microscopic characteristics such as fiber coherence and myelination in that pathway. DTT derives from measurements of anisotropic water diffusion and principal diffusion directions (Basser et al., 1994; Conturo et al., 1996), and the general observation that water preferentially diffuses along the direction of fibers (e.g., Henkelman et al., 1994; Makris et al., 1997; Stanisz et al., 1997). Using DTT, we previously identified 
and traced pathways interconnecting medial-temporal lobe and mid-fusiform gyrus in typical adults (Smith et al., 2003, 2005, 2008). There have been a few reported DT-MRI studies of autism (Alexander et al., 2007; Barnea-Goraly et al., 2004; Ben Bashat et al., 2007; Keller et al., 2007; Lee et al., 2007) and one DTT study (Catani et al., 2008); however, none of these studies used DTT to identify and analyze pathways interconnecting medial-temporal lobe and mid-fusiform gyrus.

The purpose of this study was to use DT-MRI and DTT to investigate the integrity of white matter pathways involved in face processing, that is, the hippocampo-fusiform (HF) and amygdalo-fusiform (AF) pathways, in high-functioning individuals with autism and pair-wise matched controls. We also compared DTT-based measures of microstructural integrity to relevant behavioral performance measures.

\section{METHODS}

\section{Participants}

The two subject groups were composed of 17 highfunctioning adolescents/adults with autism (14 males; 3 females) and 17 normal adolescent/adult controls, pairwise matched for gender, ethnicity, handedness, age (within 3 years), Verbal IQ (VIQ), Performance IQ (PIQ), and FullScale IQ (FSIQ) [within 15 points (1 standard deviation, SD) for each IQ score] based on the Wechsler Abbreviated Scale of Intelligence (WASI, Wechsler, 1999). Pair-wise matching was pursued to address the impact of age/IQ on DT-MRI. Demographic, psychometric, and matching statistics are in Table 1. The sample was restricted to individuals with high-functioning autism (e.g., PIQ/VIQ/FSIQ $\geq 80$ ) to ensure cooperation for scanning, matchability to normal controls, and low likelihood of associated disorders. All autism participants and most controls were recruited through the Subject Core of the University of Pittsburgh Collaborative Program of Excellence in Autism (CPEA) funded by the National Institutes of Health.

All participants with autism met all criteria on the Autism Diagnostic Observation Schedule (ADOS, Lord et al., 2000) for autism, e.g., for Communication (cutoff, 3; range, 3-7), Reciprocal Social Interaction (cutoff, 6; range, 7-13) and Total (cutoff, 10; range, 10-18) algorithm scores. Additionally, these participants met autism criteria on the Autism Diagnostic Interview-Revised (ADI-R, Lord et al., 1994) including age of onset. The diagnosis of autism was confirmed by expert opinion (N.J.M. or D.L.W.). The participants with autism did not have associated or causative chromosomal, neurologic, or infectious conditions, were in good medical health, and had no history of seizures, birth injury, or head trauma. Medication histories are in Table 1. (See Supplement for relevant medication exclusion criteria and discussion of medication effects, which can be viewed online at www.journals.cambridge.org/ins.)

Controls were recruited to individually match the autism participants. Candidates were prescreened with question- naires regarding current/past personal and family history of medical/neurological/psychiatric disorders. Inclusion criteria were good physical health, no regular CNS medications, good school/job record, and good peer relationships based on parent- or self-report and staff observations during eligibility testing. Exclusion criteria were personal history of neuropsychiatric disorders, learning disability, or brain injury at/after birth; first-degree family history of developmental cognitive disorders or mood/anxiety disorders (other than a single episode of situational depression in one first-degree relative); and autism in first-, second-, or third-degree relatives. All participants in both groups were prescreened for history of metal, claustrophobia, or weight $\geq$ $114 \mathrm{~kg}$. The Institutional Review Boards at the two sites approved the study. Written informed consent was obtained from all participants after explaining all procedures.

\section{Behavioral Testing}

Handedness was determined using the Lateral Dominance Examination (Halstead-Reitan Neuropsychological Test Battery, Reitan \& Wolfson, 1993). Trained research technicians administered WASI IQ testing. There were no statistical group differences for PIQ/VIQ/FSIQ (Table 1). Face recognition was assessed with the Benton Facial Recognition Test (Benton et al., 1983), where participants match front/ side views of faces photographed under identical/altered lighting conditions. The autism group scored slightly lower than controls on this test (Table 1). Using IQ and Benton scores, subject groups were divided into lower- and higherperformance subgroups for further analysis (see Results). The relatively small number of autism participants having lower Benton scores is consistent with previous reports of young adults with high-functioning autism (Humphreys et al., 2007), and is due to several factors: participants with autism may attain correct responses by taking more time; relying on facial feature information that is not controlled for in this test (Duchaine \& Weidenfeld, 2003); or using other compensatory brain regions (Hubl et al., 2003; Pierce et al., 2001; Schultz et al., 2000). Such effects can be reduced using subtle face recognition tests (Rump et al., 2008). Because these compensatory skills improve with age in autism (Gastgeb et al., 2006), older age groups perform better. Thus, while low Benton scores indicate abnormal face processing, high Benton scores could indicate compensatory processing. Accordingly, the lower-Benton autism subgroup mostly contains individuals with abnormal face processing, while the higher-Benton subgroup contains individuals with normal and abnormal face processing.

\section{MRI Scan Sites}

All 17 autism participants and 13/17 control participants were recruited and behaviorally tested in Pittsburgh; 4 controls were recruited and behaviorally tested in St. Louis. All individuals were scanned at their site of behavioral testing, except for two autism participants scanned in St. Louis to 
Table 1. Demographics, behavioral data, and medication history

\begin{tabular}{|c|c|c|c|c|c|c|c|c|c|c|}
\hline Match \# & Scan site & $\begin{array}{c}\text { age } \\
\text { (years) }\end{array}$ & Ethnicity & Gender & Handedness & VIQ & PIQ & FSIQ & Benton score & Medications (within 3 years of MRI) \\
\hline \multicolumn{11}{|c|}{ autism group } \\
\hline 1 & Pgh & 22.19 & White & $\mathrm{M}$ & $\mathrm{R}$ & 107 & 108 & 108 & 29 & strattera (atomoxetine) [for ADHD] \\
\hline 2 & Pgh & 22.05 & White & $\mathrm{M}$ & $\mathrm{R}$ & 97 & 102 & 100 & 44 & paxil (paroxetine) [SSRI] \\
\hline 3 & Pgh & 25.70 & White & $\mathrm{M}$ & $\mathrm{R}$ & 116 & 116 & 118 & 46 & none \\
\hline 4 & Pgh & 20.02 & White & $\mathrm{M}$ & $\mathrm{R}$ & 95 & 95 & 95 & 34 & seroquel (quetiapine) [antipsychotic] \\
\hline 5 & Pgh & 22.34 & White & $\mathrm{M}$ & $\mathrm{R}$ & 83 & 132 & 105 & 48 & tegretol (carbamazepine) [anticonvuisant]: cymbalta (duloxetine) [SNRI] \\
\hline 6 & Pgh & 21.90 & White & $\mathrm{F}$ & $\mathrm{R}$ & 96 & 106 & 101 & 42 & allegra, zyrtec, claritin [for allergy]; naproxen [NSAID] \\
\hline 7 & Pgh & 23.84 & White & $\mathrm{M}$ & $\mathrm{R}$ & 93 & 105 & 99 & 41 & none \\
\hline 8 & Pgh & 32.90 & White & $\mathrm{M}$ & $\mathrm{L}$ & 104 & 116 & 110 & 48 & none \\
\hline 9 & StL & 39.61 & White & $\mathrm{F}$ & $\mathrm{R}$ & 109 & 80 & 94 & 40 & none \\
\hline 10 & StL & 53.40 & White & $\mathrm{F}$ & $\mathrm{R}$ & 110 & 107 & 110 & 45 & [thyroid medication] \\
\hline 11 & Pgh & 22.52 & White & $\mathrm{M}$ & $\mathrm{R}$ & 112 & 117 & 116 & 51 & concerta (methylphenidate) [for ADHD]; remeron (mirtazapine) [NaSSA] \\
\hline 12 & Pgh & 18.15 & White & $\mathrm{M}$ & $\mathrm{R}$ & 111 & 121 & 118 & 48 & none \\
\hline 13 & Pgh & 17.69 & White & $\mathrm{M}$ & $\mathrm{R}$ & 95 & 101 & 98 & 50 & none \\
\hline 14 & Pgh & 49.15 & White & $\mathrm{M}$ & $\mathrm{R}$ & 88 & 103 & 96 & 44 & none \\
\hline 15 & Pgh & 22.67 & White & $\mathrm{M}$ & $\mathrm{R}$ & 83 & 110 & 96 & 43 & celexa (citalopram) $[\mathrm{SSRI}]$; multivitamin, vitamin $\mathrm{E}$ \\
\hline 16 & Pgh & 19.15 & White & $\mathrm{M}$ & $\mathrm{R}$ & 109 & 88 & 99 & 43 & none \\
\hline \multirow[t]{3}{*}{17} & Pgh & 16.52 & Asian & $\mathrm{M}$ & $\mathrm{R}$ & 104 & 119 & 112 & 40 & prozac (fluoxetine) [SSRI] \\
\hline & Mean $=$ & 26.46 & & & & 100.71 & 107.41 & 104.41 & 43.29 & \\
\hline & $\mathrm{SEM}=$ & 2.73 & & & & 2.58 & 3.16 & 2.08 & 1.40 & \\
\hline \multicolumn{11}{|c|}{ control group } \\
\hline 1 & Pgh & 24.14 & White & $\mathrm{M}$ & $\mathrm{R}$ & 111 & 116 & 115 & 42 & none \\
\hline 2 & Pgh & 24.84 & White & $\mathrm{M}$ & $\mathrm{R}$ & 105 & 112 & 109 & 45 & none \\
\hline 3 & Pgh & 23.05 & White & $\mathrm{M}$ & $\mathrm{R}$ & 107 & 114 & 111 & 51 & methotrexate/folate, chloroquine $[$ for arthritis], ranitidine $[\mathrm{H} 2]$ \\
\hline 4 & Pgh & 20.64 & White & $\mathrm{M}$ & $\mathrm{R}$ & 102 & 103 & 103 & 43 & none \\
\hline 5 & StL & 19.77 & White & M & $\mathrm{R}$ & 93 & 117 & 105 & 48 & none \\
\hline 6 & Pgh & 19.39 & White & $\mathrm{F}$ & $\mathrm{R}$ & 95 & 109 & 92 & 44 & none \\
\hline 7 & Pgh & 23.73 & White & $\mathrm{M}$ & $\mathrm{R}$ & 89 & 109 & 99 & 40 & none \\
\hline 8 & Pgh & 32.35 & White & $\mathrm{M}$ & $\mathrm{L}$ & 94 & 116 & 105 & 46 & none \\
\hline 9 & $\mathrm{StL}$ & 36.61 & White & $\mathrm{F}$ & $\mathrm{R}$ & 119 & 96 & 108 & - & none \\
\hline 10 & Pgh & 50.86 & White & $\mathrm{F}$ & $\mathrm{R}$ & 115 & 112 & 116 & 42 & none \\
\hline 11 & Pgh & 22.56 & White & $\mathrm{M}$ & $\mathrm{R}$ & 116 & 114 & 117 & 51 & none \\
\hline 12 & $\mathrm{StL}$ & 19.75 & White & M & $\mathrm{R}$ & 105 & 120 & 113 & - & none \\
\hline 13 & Pgh & 16.49 & White & $\mathrm{M}$ & $\mathrm{R}$ & 88 & 88 & 86 & 40 & sulfacetamide, clindamycin, tazarotene, azeleic acid [for skin] \\
\hline 14 & Pgh & 51.77 & White & $\mathrm{M}$ & $\mathrm{R}$ & 97 & 91 & 93 & 47 & none \\
\hline 15 & Pgh & 21.67 & White & $\mathrm{M}$ & $\mathrm{R}$ & 96 & 106 & 101 & 41 & minocychne [for skin] \\
\hline 16 & Pgh & 17.22 & White & $\mathrm{M}$ & $\mathrm{R}$ & 96 & 102 & 99 & 48 & none \\
\hline \multirow[t]{3}{*}{17} & $\mathrm{StL}$ & 18.48 & Asian & M & $\mathrm{R}$ & 119 & 111 & 117 & 47 & none \\
\hline & Mean $=$ & 26.08 & & & & 102.76 & 108.00 & 105.24 & 45.00 & \\
\hline & $\mathrm{SEM}=$ & 2.69 & & & & 2.59 & 2.31 & 2.34 & 0.92 & \\
\hline \multicolumn{11}{|c|}{ differences } \\
\hline & $\mathrm{p}=$ & 0.919 & & & & 0.565 & 0.878 & 0.788 & 0.162 & \\
\hline
\end{tabular}

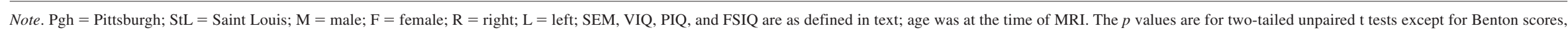

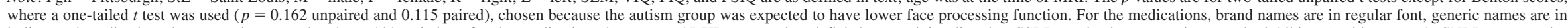

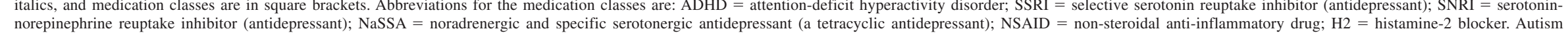
norepinephrine reuptake inhibitor (antidepressant); NaSSA $=$ noradrenergic and specific serotone
participant $\# 5$ was taking an anticonvulsant for behavioral purposes and not for a seizure disorder. 
more evenly distribute participants across scanning sites (Table 1). Some participants were re-scanned within/ across sites for scan-rescan variability analysis (see Supplement). The same person (T.E.C.) performed all scanning.

\section{DT-MRI Acquisition and DTT}

In Pittsburgh, imaging was conducted at the Frank B. Fuhrer MRI Center at University of Pittsburgh Medical CenterShadyside on a Siemens 1.5T Vision scanner. In St. Louis, imaging was conducted at Washington University School of Medicine on an identical 1.5T Vision scanner. The same procedures and parameters were used at both sites, and there were no vendor hardware/software scanner modifications during the study. Stringent customized scanner maintenance and quality control were used similarly at both sites. Participants were unsedated, positioned with ample comfort padding, and instructed to hold still (aided by tape across the forehead). Participants listened to music through acoustically shielded headphones. Participants had volunteered for previous MRI studies and/or trained in a mock scanner environment before this study.

Head positioning was similar in both groups $\left(0.07^{\circ}\right.$ difference in group-mean anterior-posterior brain tilt; $p=.976$ ). Head movement was negligible in both groups. DT-MRI data acquisition, whole-brain track computation, and pathway selection were similar to our previous studies (Conturo et al., 1999; Lori et al., 2002). Following structural MRI, DT-MRI data were acquired using a custom single-shot multislice echo-planar pulse sequence with tetrahedralorthogonal encoding (7 directions) developed in-house, with $\mathrm{TE}=94 \mathrm{~ms}, \mathrm{TR}=15.75 \mathrm{~s}, 2.5-\mathrm{mm}$ isotropic voxels (interpolated to $1.25 \times 1.25 \times 2.5-\mathrm{mm}$ ), 45 slices, and ten scan repeats collected in two 15.75 -min scans. Data were acquired without cardiac gating to shorten scan times and maximize cooperation. The same DT-MRI sequence was run at both sites, and was not modified during the study. In combination, the scanner hardware and pulse sequence provided a basic set of stable, reliable methods across the two sites and multi-year scanning period.

From the diffusion-weighted images, whole-brain track data were calculated, pathways were selected, and qualitycontrol was tested (see Supplement). The same operator performed all pathway selections, blinded to participant, with outcomes not determined until all selections were complete. The AF pathway (Fig. 1, red) projected to/from the amygdala, while the HF pathway (Fig. 1, blue) projected to/from hippocampus, confirmed on two-dimensional (2D) anatomical overlays (Fig. 1, lower). The posterior end of the pathways began/ended adjacent to mid-fusiform gyrus at the crest of, and medial to, lateral occipitotemporal sulcus.

\section{Pathway Metric Measurement}

Pathway metrics were measured from all selected pathways using in-house software. To avoid errors from anatomical variation, region sampling, and image transformation/ warping/blur, all metrics were measured in the "pathway space" determined by DTT (which was in the T2-weighted diffusion imaging data space). Two different classes of DTT metrics were measured: (1) metrics reporting macrostructural features of the overall pathway (e.g., pathway size); and (2) metrics reporting microstructural features within the pathway (e.g., fiber packing). Specifically, the measured macrostructural DTT metrics were: (a) pathway volume; (b) mean pathway length; and (c) mean pathway crosssectional area. Pathway volume was measured as the total volume of brain voxels traversed by the track lines of the pathway. Mean pathway length was calculated as mean track length. Mean cross-sectional area was calculated as volume/ mean length. These macrostructural features are on the millimeter scale. In contrast, microstructural DTT metrics are tensor parameters that describe the microscopic movements of water molecules among several adjacent axons, and relate to microscopic pathway features on the cellular (micron) scale. The two primary microstructural DTT metrics were the smallest principal diffusion coefficient (D-min) and largest principal diffusion coefficient (D-max). Secondary microstructural metrics (e.g., anisotropy, D-radial) are described in Supplement. Tensor parameters were measured at each point along the tracks within the pathway. The microstructural DTT metrics were then calculated as the average value of the parameter within that pathway.

D-min (the smallest eigenvalue of the tensor) describes the strength of water diffusion in the direction that intrinsically has the slowest diffusion (typically perpendicular to the white matter fiber axis), as sampled among several adjacent axons and averaged across the $\sim$ mm voxel dimensions. D-min describes the intrinsic across-fiber diffusion, particularly for pathways having curves/divergences (see Supplement), and can be termed the "across-fiber diffusivity." D-max (largest tensor eigenvalue) describes the strength of water diffusion in the direction that characteristically has the fastest diffusion (typically along the fiber axis). Thus, D-max can be termed the "along-fiber diffusivity," sometimes called "axial diffusivity."

Some general relations between metrics and biological features can be inferred to guide interpretation. D-min samples the resistance to across-fiber diffusion imparted by barriers such as membranes and myelin. Such barriers impede diffusion by both resisting water passage, and being closely spaced such that water molecules encounter multiple barriers during the time-scale (milliseconds) and space-scale (microns) of DT-MRI. Accordingly, a low D-min (slow across-fiber diffusion) could be due to thicker myelin (overmyelination), a more water-impermeant myelin, denser packing of fibers, and/or smaller fiber diameters. A high D-min (faster across-fiber diffusion) could be due to delayed myelination (under-myelination), loss of myelin (demyelination), more water-permeable myelin (dysmyelination), loss of axonal membrane integrity (axonal damage), more sparse packing of fibers (e.g., axonal dropout), less-coherent fiber packing (e.g., cellular remnants or incomplete pruning), and/or larger-diameter fibers. For D-max, a high value (fast 

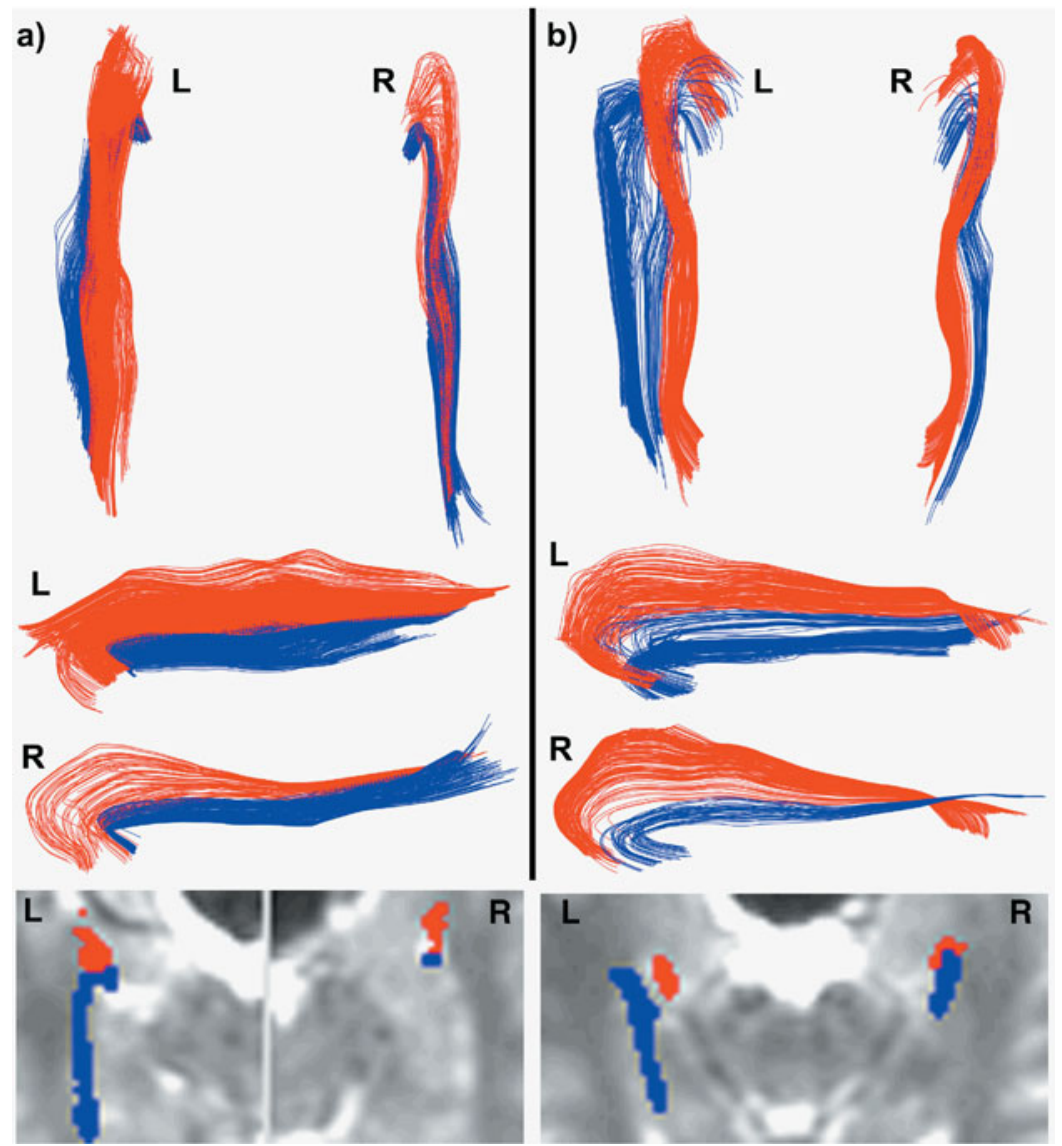

Fig. 1. Amygdalo-fusiform (red) and hippocampo-fusiform (blue) pathways for a typical matched subject pair of an autism participant (a) and control participant (b). The data are from subject pair \#7 in Table 1. Pathways are shown in three-dimensional (3D) projection display viewed from above (upper part of $a$ and $b$ ), and from the medial side (middle part of $a$ and $b$ ). The medial views of the left pathways are inverted so that the left pathway orientations are similar to the right pathways. The 2D anatomical overlays of pathways on I0 images (lower part of a and b) demonstrate the precise anatomical location of pathways with respect to T2-weighted images.

along-fiber diffusion) indicates less hindrance to water movement along axons, and could be due to axonal loss and/or less-dense fiber packing.

For each metric M, we calculate laterality (the degree to which the metric differs between the two hemispheres) as:

$$
[M(\text { left })-M(\text { right })] /[M(\text { left })+M(\text { right })] .
$$

Laterality measurements are important in their own right for providing insight into the specialization (or development) of a given brain structure in a population such as autism, in cases where that structure develops asymmetrically in controls (e.g., De Fosse et al., 2004; EscalanteMead et al., 2003; Herbert et al., 2002, 2005). Laterality calculations also control for factors that could affect pathway measurements in both hemispheres (e.g., brain water content). Finally, for each metric, we divide pathway values by the values calculated from whole-brain track data. Such whole-brain normalization controls for global changes (e.g., general developmental age), thus testing the specificity of pathway findings. Laterality and normalization cal- culations reduce variability as each individual serves as her/ his own control (normalization does not affect laterality).

\section{Statistical Testing}

Differences in group means were tested for significance using $t$ tests (JMP7.0, SAS Institute, Cary, NC). Conservatively, unpaired $t$ tests were reported for all analyses. In some cases, paired $t$ tests were also reported for comparison, treating participants as matched pairs according to the study design. Unless otherwise stated, $p$ values are for twotailed unpaired $t$ tests. All uncertainties for DTT metrics are \pm 1 SEM. Effect size (Eff) was calculated as in Supplement.

\section{Results}

\section{Pathway Shape, Location, and Size}

The AF/HF pathway system was identified in all 17 participants with autism and all 17 controls. Figure 1 shows typ- 
ical results for a matched subject pair. The pathways in the autism group had normal shape and trajectory (Fig. 1), and terminated in normal locations immediately adjacent to midfusiform area, lateral amygdala, and anterolateral hippocampus (Fig. 1, lower). One participant with autism had very small right HF and AF pathways. There were no detectible statistically-significant group differences in the macrostructural DTT metrics of pathway volume, mean pathway length, or mean cross-sectional area (see Methods). The lateralities in these three macrostructural metrics were also normal compared with controls.

\section{Primary Pathway Metrics: D-min and D-max}

The results for D-min (across-fiber diffusivity) are shown in Figure 2. There was a statistically significant shift in the laterality of the HF pathways toward a lower D-min on the right, with a loss of the normal lateralization occurring in controls (Fig. 2b), indicating an abnormality of the HF pathway system. The group-mean laterality in D-min of the HF pathways was $(+0.30 \pm 1.07) \%$ for the autism group and $(-3.95 \pm 0.92) \%$ for controls $($ Eff $=+4.25 \%$; $p=.0040$ unpaired, $p=.0017$ paired). The statistical power for detecting this finding was $85 \%$ for unpaired analysis, $91 \%$ for paired analysis. The left $\mathrm{AF}$ and HF pathways and right AF pathway had trends toward increased
D-min, while the right HF pathway had a trend toward decreased D-min (Fig. 2a). There was also a global trend of higher D-min in the whole-brain track data (autism D-min $0.3948 \pm 0.0095 \mu \mathrm{m}^{2} / \mathrm{ms}$, controls $0.3769 \pm 0.0093 \mu \mathrm{m}^{2} /$ $\mathrm{ms} ; \%$ Eff $=+4.75 \% ; p=.18$ ). Thus, the above pathway trends of increased D-min might be partially due to a global brain effect. To test for pathway-specific group differences in D-min, the whole-brain normalized D-min was calculated, which accentuated the autism-versuscontrol differences in right HF, suppressed the differences in the other three pathways (Fig. 2c), and yielded a statistically-significant D-min reduction in right HF underlying the laterality shift (autism normalized D-min $1.159 \pm$ 0.027 , controls $1.242 \pm 0.028 ; \% \mathrm{Eff}=-6.67 \% ; p=.038$ unpaired, $p=.014$ paired). The statistical power for detecting this effect was 54\% (unpaired), 73\% (paired). Type-I and Type-II error rates and paired analysis are discussed in Supplement.

For along-fiber diffusivity, all four pathways had trends toward an increased D-max in the autism group compared with controls (Fig. 3a), which was statistically significant for the right AF pathway (autism D-max $1.303 \pm 0.011 \mu \mathrm{m}^{2} /$ $\mathrm{ms}$, controls $1.264 \pm 0.013 \mu \mathrm{m}^{2} / \mathrm{ms}$, \%Eff $=3.04 \% ; p=$ .025). The D-max differences between groups were not reinforced by whole-brain normalization (Fig. 3c). See Supplement for secondary metric results.
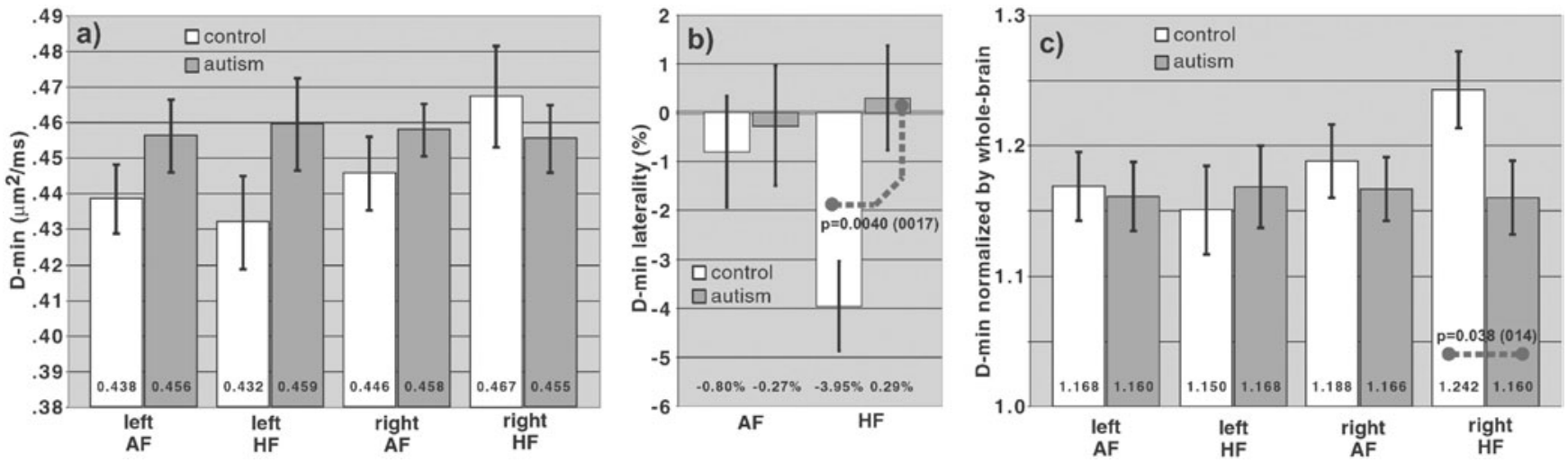

Fig. 2. Comparison of the pathway D-min in autism and control groups. a: The left amygdalo-fusiform (AF), left hippocampo-fusiform (HF), and right AF pathways show trends of an increased D-min in the autism group compared with controls (e.g., $p=.134$ unpaired and .089 paired for the left HF pathway). In contrast, the right HF shows a trend of a decreased D-min in the autism group compared with controls. b: Analysis of laterality (see Methods) shows a strong change in laterality in the HF pathway system ( $p=.0040$ unpaired, .0017 paired) with a loss of lateralization, where laterality ranges from $+100 \%$ (full left-lateralization) to 0 (no lateralization) to $-100 \%$ (full rightlateralization). Because two pathway systems ( $\mathrm{HF}$ and $\mathrm{AF}$ ) were analyzed for laterality, the Bonferroni-corrected $p$-value threshold was $.05 / 2=.025$ (to conservatively correct for multiple comparisons). c: Normalization by the whole-brain D-min value reveals that the laterality shift in (b) is predominantly due to a specific decrease in D-min in the right HF pathway in the autism group, compared with controls $(p=.038$ unpaired and .014 paired, where the corrected $p$-value threshold is 0.025 because two HF pathways are tested). This normalization effectively normalizes the pathway measurement by the average whole-brain value for white matter that has an anisotropy above the trackability threshold. Because the whole-brain D-min in the autism group is increased compared with controls (see text), the decreased D-min in the right HF pathway in (a) is accentuated in (c). In contrast, the trend of increased D-min in the three other pathways in the autism group compared with controls in (a) is suppressed in (c), because the D-min increase in these three pathways is similar to the overall whole-brain increase in D-min. Error bars are $\pm 1 \mathrm{SEM}$. The $p$ values shown in the Fig. are for unpaired $t$ tests (with $p$ values for paired comparisons given in parentheses). 

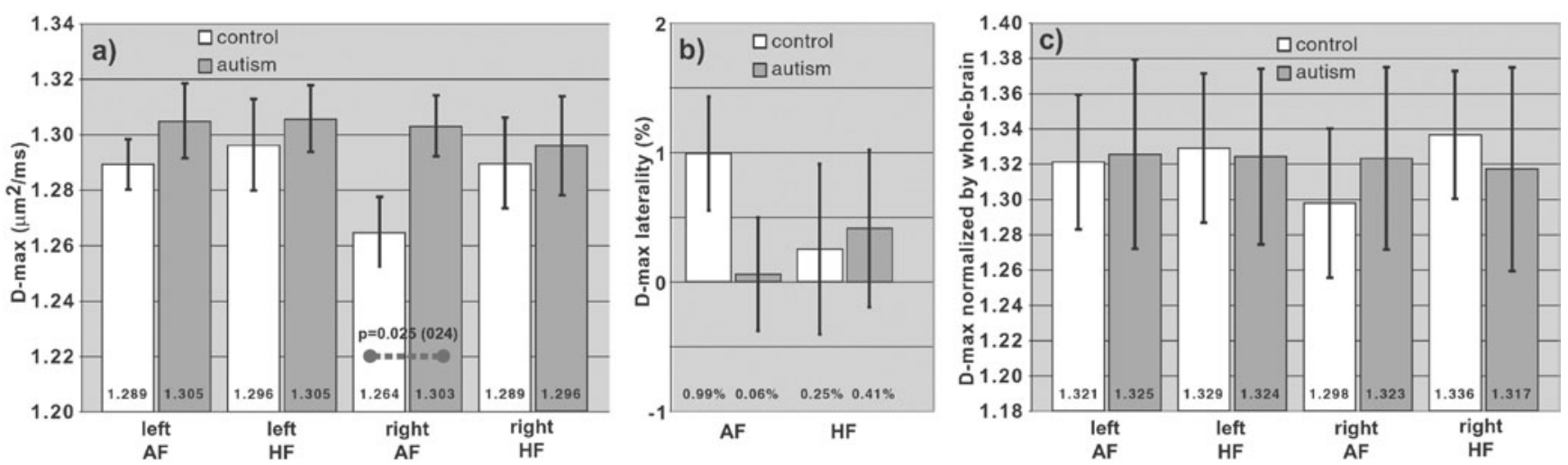

Fig. 3. Comparison of the pathway D-max in autism and control groups. a: All four pathways have a trend of increased D-max in the autism group compared with controls. b: Laterality analysis shows a trend toward loss of the normal laterality in the AF pathways in the autism group. Because the trend in (a) affects all four pathways, the effects on laterality are less than for D-min in Figure 2b. c: Normalization by the whole-brain white matter D-max value shows no significant difference in the autism and control groups, indicating that the increases in D-min in (a) are in part reflective of a more global pattern.

Although subtle, many of these observations reached statistical significance, even using the conservative unpaired $t$ test and Bonferroni threshold (Fig. 2 legend), in part due to low scan-rescan variability (see Supplement). Variability was further reduced by computing laterality and wholebrain normalization (based on scan-rescan analysis; not shown).

\section{Relation to Face Recognition Scores}

To evaluate the functional significance of the main finding of decreased D-min in right HF (Fig. 2c), we related DTT data to behavioral measures. Because the predominant function of the right HF pathway is face recognition (Smith et al., 2005), we compared the right HF D-min to Benton face-recognition scores. If the decreased D-min in right $\mathrm{HF}$ in Fig. 2c were functionally significant, one would expect a generally stronger reduction in D-min in the autism participants who have lower Benton scores. We tested this hypothesis by dividing each subject group into lower-Benton and higher-Benton subgroups using a single cutoff (scores $\leq$ 42) chosen to yield an adequate sample size in the two lower-Benton subgroups ( 6 autism $/ 5$ controls).

This subgroup analysis (Fig. 4) shows two important relationships. First, the group difference in normalized D-min seen in Figure $2 \mathrm{c}$ is accentuated when comparing the two lower-Benton subgroups. The normalized D-min was $1.108 \pm$ 0.039 in the lower-Benton autism subgroup versus $1.263 \pm$ 0.053 in the lower-Benton control subgroup (\%Eff = $-12.2 \% ; p=.014$, one-tailed), which was a stronger effect than the $-6.67 \%$ effect between the two full-subject groups (see above). Second, the autism participants in the lowerBenton subgroup on-average had a significantly reduced D-min compared with the autism participants in the higherBenton subgroup (compare the two right-most gray bars in Fig. 4), with a normalized D-min of $1.108 \pm 0.039$ (lower-
Benton) versus $1.187 \pm 0.030$ (higher-Benton; \%Eff $=$ $-6.64 \% ; p=.053$, one-tailed). In other words, the autism participants who had lower Benton scores on-average tended to have a stronger D-min reduction in right HF. In contrast, for controls there was no significant difference between lower-Benton and higher-Benton subgroups (lower-Benton $1.262 \pm 0.053$, higher-Benton $1.238 \pm 0.042 ; \%$ Eff $=$ $+1.95 \% ; p=.70)$, indicating the specificity of this DTT-

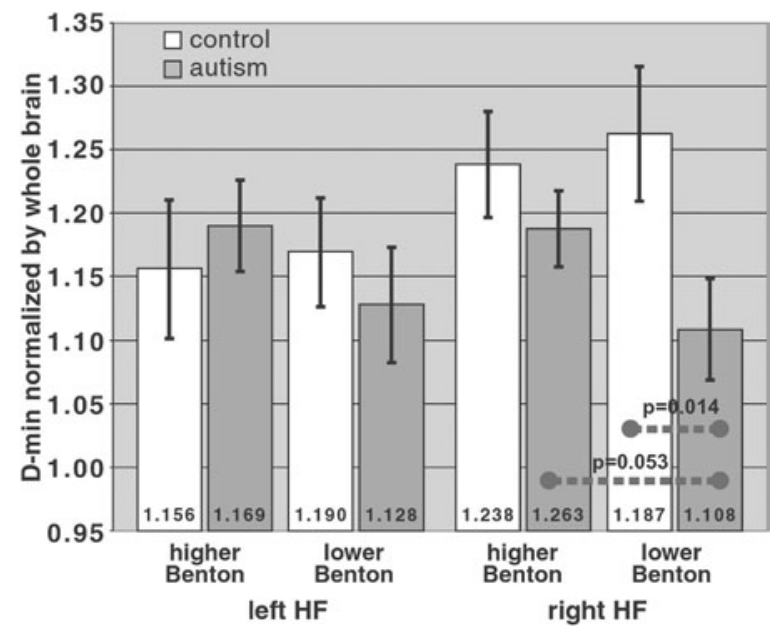

Fig. 4. Comparison of the HF pathways to Benton facial recognition test scores. For the right HF pathway, which had a reduction in the normalized D-min in the autism group compared with controls in Figure 2c, this reduction is more severe when considering the two subgroups with lower Benton scores (right-most white and gray bars), with $p=.014$ (one-tailed; corrected threshold .025 for two comparisons for the right HF pathway). Also, within the autism group, the normalized D-min in the right HF pathway was more severely reduced in the lower-Benton subgroup compared with the higher-Benton subgroup ( $p=.053$; one-tailed). 
Benton relationship to autism. Results were similar using a different lower-Benton cutoff $(\leq 41)$. Correlation analysis showed a trend of a reversed DTT-Benton relation (autism Spearman's $\rho=+0.32$; controls -0.26 ).

\section{Relation to IQ Scores}

To further evaluate the functional significance of the right HF D-min, we tested for relations between D-min and IQ. The right HF pathway is expected to subserve object recognition (as well as face recognition) functions (Smith et al., 2003, 2008). The right HF would thus be probed by the WASI PIQ score, half of which is derived from BlockDesign tasks (which involve object processing). We thus hypothesized that there is a stronger reduction in D-min in the autism participants who have lower PIQ scores, indicating the functional significance of the D-min reduction. Accordingly, as with the Benton test, we divided each subject group into lower-PIQ and higher-PIQ subgroups using a single cutoff (PIQ $\leq 109)$ to yield similar-sized subgroups (10 autism/8 controls in lower-PIQ subgroups).

The PIQ subgroup analysis (Fig. 5) revealed the same two important relationships found in the Benton subgroup analysis (Fig. 4). First, the pattern of a lower normalized $\mathrm{D}$-min in right $\mathrm{HF}$ in the autism group compared with controls (Fig. 2c) was accentuated when comparing the lowerPIQ subgroups (Fig. 5). The normalized right HF D-min in the lower-PIQ autism subgroup (1.118 \pm 0.030$)$ and lowerPIQ control subgroup $(1.237 \pm 0.048)$ were statistically different (\%Eff $=-9.65 \% ; p=.021$, one-tailed), with a

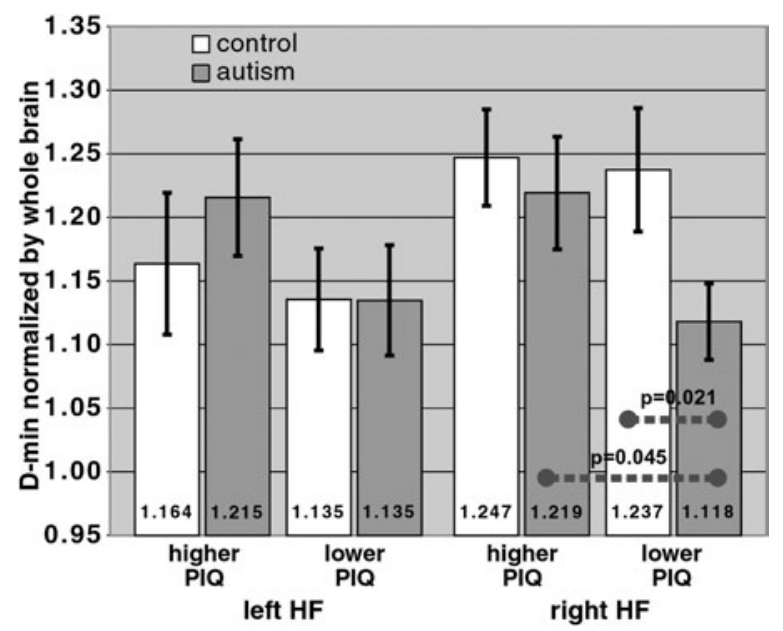

Fig. 5. Comparison of the HF pathways to performance IQ (PIQ) scores. Similar to the comparison to Benton scores (Fig. 4), the reduction in the normalized D-min in the autism group compared with controls is more severe in the subgroup that had lower PIQ scores (right-most white and gray bars), with $p=.021$ (one-tailed; corrected threshold 0.025 as in Fig. 4). Also, within the autism group, the D-min reduction was more severe in the lower-PIQ subgroup compared with the higher-PIQ subgroup $(p=.045$; one-tailed). stronger effect than for the full-group comparison $(\%$ Eff $=$ $-6.67 \%)$. Second, the normalized D-min in the lower-PIQ autism subgroup $(1.118 \pm 0.030)$ was significantly less than in the higher-PIQ autism subgroup $(1.219 \pm 0.044$; \% Eff $=$ $-8.30 \% ; p=.045$, one-tailed). As with the Benton results, the autism participants who had lower PIQ on-average tended to have lower D-min in right HF. In contrast, in controls there was no difference between lower-PIQ $(1.237 \pm 0.048)$ and higher-PIQ $(1.247 \pm 0.038)$ subgroups $(\%$ Eff $=-0.77 \%$; $p=.87$ ), indicating the specificity of this DTT-PIQ relationship to autism.

As a negative-control test, the VIQ should not relate to right HF pathway functions (because the HF language functions are exclusively on the left (Smith et al., 2005, 2008). There was no DTT-VIQ relationship ( $p=.507$ for lowerVIQ $v s$. higher-VIQ autism subgroups; cutoff VIQ $\leq 99 ; 8$ autism/8 controls in lower-VIQ subgroups), indicating the specificity of the Benton and PIQ results.

\section{DISCUSSION}

This study analyzed the macrostructure and microstructure of pathways interconnecting hippocampus/amygdala with the mid-fusiform gyrus, which comprise a neural system highly relevant to face processing deficits in autism. The main results were as follows: (1) the normal macrostructural features of the pathways (e.g., volume); (2) the specific and functionally significant reduction in D-min of the right HF pathway; and (3) the less-specific increase in D-min and D-max of the other three pathways (right AF/left HF/left $\mathrm{AF})$. The normal macrostructure, with no major gross anatomical aberrations such as absent pathways or altered trajectories, is consistent with the generally normal gross anatomy of the brain (Kemper \& Bauman, 1993) and the normal intra-cerebral white matter volume in adolescents/ adults with autism (Aylward et al., 2002; Hazlett et al., 2006; Lainhart, 2006), which contrasts with the severity of clinical manifestations. The macrostructural results suggest that the general pathway "machinery" is in place, but the microstructural/behavioral results suggest that this machinery operates abnormally.

\section{Microstructural Pathway Characteristics}

The principal finding is a slower D-min in right HF in the autism group. The decrease in D-min is an unusual finding in that the effect is opposite that of the other three pathways and whole brain. The D-min decrease in right HF is functionally significant in that the effect is consistently stronger in lower-Benton and lower-PIQ subgroups. This D-min/ behavioral relationship in right $\mathrm{HF}$ is also unusual because: the D-min/behavioral relationship is reversed compared with controls (Figs. 4, 5); and the D-min/function relationships are weaker in the other pathways (even though both pathway sides are involved in face/object processing, Smith et al., 2005, 2008). Overall, these results suggest that there 
are unique microstructural mechanisms underpinning the D-min decrease and D-min/behavioral reversal in right HF.

Typically, lower D-min reflects more myelination, which is associated with higher function (faster neural transmission). The autism group exhibited a reversal of this expected relationship (i.e., lower D-min in right HF was associated with lower Benton/PIQ scores). In total, these results indicate a characteristic, distinct pathologic process in the autism group that preferentially affects right HF and causes pathway dysfunction.

In contrast to right $\mathrm{HF}$, the other three pathways had trends of increased D-min (Fig. 2a) and D-max (Fig. 3a) versus controls (statistically significant in right $\mathrm{AF}$ ). These patterns were less specific than the right HF findings, because these D-min/D-max increases were suppressed by wholebrain normalization (Figs. 3c, 4c). These patterns thus suggest that the pathologic process in these three pathways differs somewhat from the process in right HF.

\section{Postulated Mechanism}

Because typical neuropathologic processes (e.g., demyelination, axonal loss) cause D-min increases, and because decreased D-min is usually associated with increased function (hyper-myelination), a non-myelin mechanism must be postulated for the decreased D-min in right HF. Possible causes of low D-min (decreased across-fiber diffusivity) include increased myelination, increased fiber-packing density, and decreased axon diameter. Of these mechanisms, small axon diameters would most readily decrease function, because neural conduction speed is physiologically slower for smaller-diameter axons at similar myelination (Titmus \& Faber, 1990). Thus, the right HF findings are most parsimoniously explained by smaller-diameter axons (possibly an early pathologic process), which would reduce D-min by moving water barriers closer together. Alternatively, increased packing density (i.e., closer packing) and/or coherence could explain the findings, without diameter changes, but a relation to decreased function is less clear. A combination of changes could also occur, such as decreased diameter with increased packing density (histologically reported for hippocampal cell bodies, Bauman \& Kemper, 2005), with both changes cooperatively reducing D-min.

Increased D-min/D-max suggests a different process in the other pathways. The best explanation for those pathways is myelination decrease and/or axonal loss (possibly a later, secondary process), both of which would increase D-min/D-max. Axonal loss in amygdala was reported histologically (Schumann \& Amaral, 2006). The mechanism of myelination decrease/axonal loss in those pathways could be a more severe manifestation of global brain changes. Mixed effects are also possible, with a diameter component superimposed on the effects of myelination/axonal loss, whereupon the measured D-min would reflect the dominant mechanism (e.g., see right AF, Figs. 2c, 3).

All observations in Figures 2, 3 fit this overall mechanism (even though only some observations reach statistical significance in isolation), supporting the proposed mechanism. Alternative mechanisms are also possible, such as change in axoplasm, or increased right HF myelination from years of cognitive effort in the setting of long-term faceprocessing impairments. However, such cognitive mechanisms are less consistent with the stronger D-min reduction in the lower-Benton subgroup (Fig. 4), and the contrast between right/left HF pathways (Fig. 2b; both pathways being involved in face processing). Future study of younger children could help differentiate these mechanisms.

The finding of a characteristic right HF process suggesting small-diameter axons is consistent with several lines of evidence. First, histologic studies reported small hippocampal cell bodies resembling an earlier maturational state, alluding to curtailed development in autism (Bauman \& Kemper, 2005). Second, Casanova et al. (2002) observed small neuronal cell bodies in cortical minicolumns. Smaller cell bodies typically project smaller-diameter axons (M. Casanova, Personal Communication, 7/3/2007). Third, face recognition impairments occur very early in autism (Adolphs et al., 2001; Celani et al., 1999; Dawson et al., 2002, 2004; Gepner et al., 1996; Klin et al., 1999), consistent with an early abnormality in right HF (and also compatible with cognitive mechanisms). Fourth, small-diameter axons are consistent with reduced functional correlations in $\mathrm{fMRI}$, because slower transmission of information in small-diameter axons would reduce synchrony between regions. This mechanism is also consistent with fMRI observations that some autism participants use alternative brain mechanism to process faces (Hubl et al., 2003; Pierce et al., 2001; Schultz et al., 2000), which could bypass an abnormal right HF. Fifth, slower reaction times and increased brain-potential latencies (slower processing speed) were observed in autism during tasks including face processing (Harris et al., 1999; McPartland et al., 2004; Tardif et al., 2007; Townsend et al., 1996). Last, a recent study suggests that autism symptoms can improve during febrile episodes (Curran et al., 2007). It is possible that known physiologic temperature effects on nerve conduction velocity (e.g., Rutkove, 2001; Tasaki \& Fujita, 1948) could accelerate transmission sufficiently to improve function.

The results herein also link broadly with other published studies. The hippocampus/amygdala were found to be involved in early brain over-growth, and to have alterations in $\mathrm{fMRI}$ activation in autism (see Introduction). Previous DT-MRI/DTT studies of older children, adolescents, and adults with autism found decreased anisotropy in/near corpus callosum (Alexander et al., 2007; Barnea-Goraly et al., 2004; Keller et al., 2007), in superior cerebellar peduncles (Catani et al., 2008), and in temporal (Barnea-Goraly et al., 2004; Lee et al., 2007) and frontal (Barnea-Goraly et al., 2004) regions, with concomitant D-radial increases reported in some cases (Alexander et al., 2007; Lee et al., 2007). One study (Barnea-Goraly et al., 2004) detected lower anisotropy near amygdala bilaterally, which could relate to the findings in AF pathways. These reports are consistent with the DTT changes in right $\mathrm{AF}$ and left $\mathrm{AF} / \mathrm{HF}$, except that 
we observed small changes in anisotropy due to D-max and D-min both increasing, suggesting a component of axonal loss (Lee et al., 2007 reported no change in D-max). The decrease in anisotropy reported over several regions is consistent with our observed whole-brain D-min increase. D-min reductions (or anisotropy increases), as found herein using pathway-specific measurements, were not reported in the above studies. However, one DT-MRI study of 1.8- to 3.3year-old children with autism (Ben Bashat et al., 2007) using sedation did report diffuse anisotropy increases, which the authors attributed to accelerated white matter maturation. It is interesting to consider whether those findings and the right $\mathrm{HF}$ findings might be related (e.g., persistency of high anisotropy/low D-min from early childhood).

\section{SUMMARY}

This DTT study constitutes an initial attempt to explore the microstructure of key pathways related to face/emotion processing in autism. The definition of relevant pathways interconnecting medial-temporal and mid-fusiform structures, the precise quantitative measurement of various macro- and microstructural pathway features, and the demonstration that comparisons to behavioral measures can provide meaningful neurobiological insights, represent significant technological advances. A wider range of the autism spectrum needs to be studied to extrapolate the findings to lowerfunctioning autism, and more-specific behavioral measures are needed to refine interpretations. Nonetheless, the findings provide feasibility and new insights into neurobiologic disturbances in autism.

\section{ACKNOWLEDGMENTS}

We thank Siemens Medical Solutions for providing memory hardware for MRI, and the University of Pittsburgh Medical CenterShadyside/Frank B. Fuhrer MRI Center for providing additional scanner disks and scanner maintenance. We thank Dr. Manuel Casanova and Dr. Mark Strauss for helpful discussions; and Patricia McCarroll, Kimberly Bodner, Dana Romo, Katie Schupp, Karen Pusczek, and Amanda McMichael for subject recruitment, behavioral testing, assisting with MRI scanning, data entry, and editing; and Dr. Charles Hildebolt and Emily Williams for statistical assistance. This work was supported primarily by The Nancy Lurie Marks Family Foundation and also by: NIH ACE grant P50 HD55748 and CPEA grant U19 HD35469; NIH grants R01 NS39538, K23 DC06691, R01 AG09862, R01 NS36660, R01 NS52470, P20 MH71616, AS03799; and private donations. Computations used product equipment previously provided by Sun Microsystems. The authors of this work have no significant financial conflicts of interest.

\section{REFERENCES}

Adolphs, R., Tranel, D., \& Damasio, H. (2001). Emotion recognition from faces and prosody following temporal lobectomy. Neuropsychology, 15, 396-404.

Alexander, A.L., Lee, J.E., Lazar, M., Boudos, R., Dubray, M.B., Oakes, T.R., Miller, J.N., Lu, J., Jeong, E.K., McMahon, W.M.,
Bigler, E.D., \& Lainhart, J.E. (2007). Diffusion tensor imaging of the corpus callosum in autism. Neuroimage, 34, 61-73.

Ashwin, C., Baron-Cohen, S., Wheelwright, S., O'Riordan, M., \& Bullmore, E.T. (2007). Differential activation of the amygdala and the 'social brain' during fearful face-processing in Asperger Syndrome. Neuropsychologia, 45, 2-14.

Aylward, E.H., Minshew, N.J., Field, K., Sparks, B.F., \& Singh, N. (2002). Effects of age on brain volume and head circumference in autism. Neurology, 59, 175-183.

Aylward, E.H., Minshew, N.J., Goldstein, G., Honeycutt, N.A., Augustine, A.M., Yates, K.O., Barta, P.E., \& Pearlson, G.D. (1999). MRI volumes of amygdala and hippocampus in nonmentally retarded autistic adolescents and adults. Neurology, $53,2145-2150$.

Barnea-Goraly, N., Kwon, H., Menon, V., Eliez, S., Lotspeich, L., \& Reiss, A.L. (2004). White matter structure in autism: Preliminary evidence from diffusion tensor imaging. Biological Psychiatry, 55, 323-326.

Baron-Cohen, S., Ring, H.A., Wheelwright, S., Bullmore, E.T., Brammer, M.J., Simmons, A., \& Williams, S.C. (1999). Social intelligence in the normal and autistic brain: An fMRI study. The European Journal of Neuroscience, 11, 1891-1898.

Basser, P.J., Mattiello, J., \& Le Bihan, D. (1994). Estimation of the effective self-diffusion tensor from the NMR spin echo. Journal of Magnetic Resonance. Series B, 103, 247-254.

Bauman, M.L. \& Kemper, T.L. (2005). Neuroanatomic observations of the brain in autism: A review and future directions. International Journal of Developmental Neuroscience, 23, 183-187.

Belmonte, M.K., Allen, G., Beckel-Mitchener, A., Boulanger, L.M., Carper, R.A., \& Webb, S.J. (2004). Autism and abnormal development of brain connectivity. The Journal of Neuroscience, 24, 9228-9231.

Ben Bashat, D., Kronfeld-Duenias, V., Zachor, D.A., Ekstein, P.M., Hendler, T., Tarrasch, R., Even, A., Levy, Y., \& Ben Sira, L. (2007). Accelerated maturation of white matter in young children with autism: A high b value DWI study. Neuroimage, 37, 40-47.

Benton, A.L., Sivan, A.B., Hamsher, K., Varney, N.R., \& Spreen, O. (1983). Benton Facial Recognition: Stimulus and Multiple Choice Pictures. Lutz, FL: Psychological Assessment Resources Inc.

Casanova, M.F., Buxhoeveden, D., \& Gomez, J. (2003). Disruption in the inhibitory architecture of the cell minicolumn: Implications for autism. The Neuroscientist, 9, 496-507.

Casanova, M.F., Buxhoeveden, D.P., Switala, A.E., \& Roy, E. (2002). Minicolumnar pathology in autism. Neurology, 58, 428-432.

Casanova, M.F., van Kooten, I.A., Switala, A.E., van Engeland, H., Heinsen, H., Steinbusch, H.W., Hof, P.R., Trippe, J., Stone, J., \& Schmitz, C. (2006). Minicolumnar abnormalities in autism. Acta Neuropathologica, 112, 287-303.

Catani, M., Jones, D.K., Daly, E., Embiricos, N., Deeley, Q., Pugliese, L., Curran, S., Robertson, D., \& Murphy, D.G. (2008). Altered cerebellar feedback projections in Asperger syndrome. Neuroimage, 41, 1184-1191.

Celani, G., Battacchi, M.W., \& Arcidiacono, L. (1999). The understanding of the emotional meaning of facial expressions in people with autism. Journal of Autism and Developmental Disorders, 29, 57-66.

Conturo, T.E., Lori, N.F., Cull, T.S., Akbudak, E., Snyder, A.Z., Shimony, J.S., McKinstry, R.C., Burton, H., \& Raichle, M.E. 
(1999). Tracking neuronal fiber pathways in the living human brain. Proceedings of the National Academy of Sciences of the United States of America, 96, 10422-10427.

Conturo, T.E., McKinstry, R.C., Akbudak, E., \& Robinson, B.H. (1996). Encoding of anisotropic diffusion with tetrahedral gradients: A general mathematical diffusion formalism and experimental results. Magnetic Resonance in Medicine, 35, 399-412.

Courchesne, E., Karns, C.M., Davis, H.R., Ziccardi, R., Carper, R.A., Tigue, Z.D., Chisum, H.J., Moses, P., Pierce, K., Lord, C., Lincoln, A.J., Pizzo, S., Schreibman, L., Haas, R.H., Akshoomoff, N.A., \& Courchesne, R.Y. (2001). Unusual brain growth patterns in early life in patients with autistic disorder: An MRI study. Neurology, 57, 245-254.

Critchley, H.D., Daly, E.M., Bullmore, E.T., Williams, S.C., Van Amelsvoort, T., Robertson, D.M., Rowe, A., Phillips, M., McAlonan, G., Howlin, P., \& Murphy, D.G. (2000). The functional neuroanatomy of social behaviour: Changes in cerebral blood flow when people with autistic disorder process facial expressions. Brain, 123(Pt 11), 2203-2212.

Curran, L.K., Newschaffer, C.J., Lee, L.C., Crawford, S.O., Johnston, M.V., \& Zimmerman, A.W. (2007). Behaviors associated with fever in children with autism spectrum disorders. Pediatrics, 120, e1386-e1392.

Dalton, K.M., Nacewicz, B.M., Johnstone, T., Schaefer, H.S., Gernsbacher, M.A., Goldsmith, H.H., Alexander, A.L., \& Davidson, R.J. (2005). Gaze fixation and the neural circuitry of face processing in autism. Nature Neuroscience, 8, 519-526.

Dawson, G., Carver, L., Meltzoff, A.N., Panagiotides, H., McPartland, J., \& Webb, S.J. (2002). Neural correlates of face and object recognition in young children with autism spectrum disorder, developmental delay, and typical development. Child Development, 73, 700-717.

Dawson, G., Toth, K., Abbott, R., Osterling, J., Munson, J., Estes, A., \& Liaw, J. (2004). Early social attention impairments in autism: Social orienting, joint attention, and attention to distress. Developmental Psychology, 40, 271-283.

De Fosse, L., Hodge, S.M., Makris, N., Kennedy, D.N., Caviness, V.S., Jr., McGrath, L., Steele, S., Ziegler, D.A., Herbert, M.R., Frazier, J.A., Tager-Flusberg, H., \& Harris, G.J. (2004). Language-association cortex asymmetry in autism and specific language impairment. Annals of Neurology, 56, 757-766.

Duchaine, B.C. \& Weidenfeld, A. (2003). An evaluation of two commonly used tests of unfamiliar face recognition. Neuropsychologia, 41, 713-720.

Escalante-Mead, P.R., Minshew, N.J., \& Sweeney, J.A. (2003). Abnormal brain lateralization in high-functioning autism. Journal of Autism and Developmental Disorders, 33, 539-543.

Gastgeb, H.Z., Strauss, M.S., \& Minshew, N.J. (2006). Do individuals with autism process categories differently? The effect of typicality and development. Child Development, 77, 1717-1729.

Gepner, B., de Gelder, B., \& de Schonen, S. (1996). Face processing in autistics: Evidence for a generalised deficit? Child Neuropsychology, 2, 123-139.

Grelotti, D.J., Klin, A.J., Gauthier, I., Skudlarski, P., Cohen, D.J., Gore, J.C., Volkmar, F.R., \& Schultz, R.T. (2005). fMRI activation of the fusiform gyrus and amygdala to cartoon characters but not to faces in a boy with autism. Neuropsychologia, $43,373-385$.

Hadjikhani, N., Joseph, R.M., Snyder, J., Chabris, C.F., Clark, J., Steele, S., McGrath, L., Vangel, M., Aharon, I., Feczko, E.,
Harris, G.J., \& Tager-Flusberg, H. (2004). Activation of the fusiform gyrus when individuals with autism spectrum disorder view faces. Neuroimage, 22, 1141-1150.

Hadjikhani, N., Joseph, R.M., Snyder, J., \& Tager-Flusberg, H. (2007). Abnormal activation of the social brain during face perception in autism. Human Brain Mapping, 28, 441-449.

Harris, N.S., Courchesne, E., Townsend, J., Carper, R.A., \& Lord, C. (1999). Neuroanatomic contributions to slowed orienting of attention in children with autism. Cognitive Brain Research, 8 , 61-71.

Hazlett, H.C., Poe, M.D., Gerig, G., Smith, R.G., \& Piven, J. (2006). Cortical gray and white brain tissue volume in adolescents and adults with autism. Biological Psychiatry, 59, 1-6.

Hazlett, H.C., Poe, M., Gerig, G., Smith, R.G., Provenzale, J., Ross, A., Gilmore, J., \& Piven, J. (2005). Magnetic resonance imaging and head circumference study of brain size in autism: Birth through age 2 years. Archives of General Psychiatry, 62, 1366-1376.

Henkelman, R.M., Stanisz, G.J., Kim, J.K., \& Bronskill, M.J. (1994). Anisotropy of NMR properties of tissues. Magnetic Resonance in Medicine, 32, 592-601.

Herbert, M.R., Harris, G.J., Adrien, K.T., Ziegler, D.A., Makris, N., Kennedy, D.N., Lange, N.T., Chabris, C.F., Bakardjiev, A., Hodgson, J., Takeoka, M., Tager-Flusberg, H., \& Caviness Jr., V.S. (2002). Abnormal asymmetry in language association cortex in autism. Annals of Neurology, 52, 588-596.

Herbert, M.R., Ziegler, D.A., Deutsch, C.K., O’Brien, L.M., Kennedy, D.N., Filipek, P.A., Bakardjiev, A.I., Hodgson, J., Takeoka, M., Makris, N., \& Caviness Jr., V.S. (2005). Brain asymmetries in autism and developmental language disorder: A nested whole-brain analysis. Brain, 128, 213-226.

Herbert, M.R., Ziegler, D.A., Deutsch, C.K., O’Brien, L.M., Lange, N., Bakardjiev, A., Hodgson, J., Adrien, K.T., Steele, S., Makris, N., Kennedy, D., Harris, G.J., \& Caviness Jr., V.S. (2003). Dissociations of cerebral cortex, subcortical and cerebral white matter volumes in autistic boys. Brain, 126, 1182-1192.

Herbert, M.R., Ziegler, D.A., Makris, N., Filipek, P.A., Kemper, T.L., Normandin, J.J., Sanders, H.A., Kennedy, D.N., \& Caviness, V.S., Jr. (2004). Localization of white matter volume increase in autism and developmental language disorder. Annals of Neurology, 55, 530-540.

Hubl, D., Bolte, S., Feineis-Matthews, S., Lanfermann, H., Federspiel, A., Strik, W., Poustka, F., \& Dierks, T. (2003). Functional imbalance of visual pathways indicates alternative face processing strategies in autism. Neurology, 61, 1232-1237.

Humphreys, K., Hassan, U., Avidan, G., Minshew, N., \& Behrmann, M. (2008). Cortical patterns of category-selective activation for faces, places, and objects in adults with autism. Autism Research, 1, 52-83.

Humphreys, K., Minshew, N., Leonard, G.L., \& Behrmann, M. (2007). A fine-grained analysis of facial expression processing in high-functioning adults with autism. Neuropsychologia, 45 , 685-695.

Just, M.A., Cherkassky, V.L., Keller, T.A., Kana, R.K., \& Minshew, N.J. (2007). Functional and anatomical cortical underconnectivity in autism: Evidence from an fMRI study of an executive function task and corpus callosum morphometry. Cerebral Cortex, 17, 951-961.

Just, M.A., Cherkassky, V.L., Keller, T.A., \& Minshew, N.J. (2004). Cortical activation and synchronization during sentence comprehension in high-functioning autism: Evidence of underconnectivity. Brain, 127, 1811-1821. 
Kana, R.K., Keller, T.A., Cherkassky, V.L., Minshew, N.J., \& Just, M.A. (2006). Sentence comprehension in autism: Thinking in pictures with decreased functional connectivity. Brain, 129, 2484-2493.

Kana, R.K., Keller, T.A., Minshew, N.J., \& Just, M.A. (2007). Inhibitory control in high-functioning autism: Decreased activation and underconnectivity in inhibition networks. Biological Psychiatry, 62, 198-206.

Keller, T.A., Kana, R.K., \& Just, M.A. (2007). A developmental study of the structural integrity of white matter in autism. Neuroreport, 18, 23-27.

Kemper, T.L. \& Bauman, M.L. (1993). The contribution of neuropathologic studies to the understanding of autism. Neurologic Clinics, 11, 175-187.

Kleinhans, N.M., Richards, T., Sterling, L., Stegbauer, K.C., Mahurin, R., Johnson, L.C., Greenson, J., Dawson, G., \& Aylward, E. (2008). Abnormal functional connectivity in autism spectrum disorders during face processing. Brain, 131, 1000-1012.

Klin, A., Sparrow, S.S., de Bildt, A., Cicchetti, D.V., Cohen, D.J., \& Volkmar, F.R. (1999). A normed study of face recognition in autism and related disorders. Journal of Autism and Developmental Disorders, 29, 499-508.

Koshino, H., Carpenter, P.A., Minshew, N.J., Cherkassky, V.L., Keller, T.A., \& Just, M.A. (2005). Functional connectivity in an fMRI working memory task in high-functioning autism. Neuroimage, 24, 810-821.

Koshino, H., Kana, R.K., Keller, T.A., Cherkassky, V.L., Minshew, N.J., \& Just, M.A. (2008). FMRI investigation of working memory for faces in autism: Visual coding and underconnectivity with frontal areas. Cerebral Cortex, 18, 289-300.

Lainhart, J.E. (2006). Advances in autism neuroimaging research for the clinician and geneticist. American Journal of Medical Genetics Part C. Seminars in Medical Genetics, 142, 33-39.

Lee, J.E., Bigler, E.D., Alexander, A.L., Lazar, M., DuBray, M.B., Chung, M.K., Johnson, M., Morgan, J., Miller, J.N., McMahon, W.M., Lu, J., Jeong, E.K., \& Lainhart, J.E. (2007). Diffusion tensor imaging of white matter in the superior temporal gyrus and temporal stem in autism. Neuroscience Letters, 424, 127-132.

Lord, C., Risi, S., Lambrecht, L., Cook, E.H., Jr., Leventhal, B.L., DiLavore, P.C., Pickles, A., \& Rutter, M. (2000). The autism diagnostic observation schedule-generic: A standard measure of social and communication deficits associated with the spectrum of autism. Journal of Autism and Developmental Disorders, 30, 205-223.

Lord, C., Rutter, M., \& Le Couteur, A. (1994). Autism Diagnostic Interview-Revised: A revised version of a diagnostic interview for caregivers of individuals with possible pervasive developmental disorders. Journal of Autism and Developmental Disorders, 24, 659-685.

Lori, N.F., Akbudak, E., Shimony, J.S., Cull, T.S., Snyder, A.Z., Guillory, R.K., \& Conturo, T.E. (2002). Diffusion tensor fiber tracking of human brain connectivity: Aquisition methods, reliability analysis and biological results. NMR in Biomedicine, 15, 494-515.

Luna, B., Minshew, N.J., Garver, K.E., Lazar, N.A., Thulborn, K.R., Eddy, W.F., \& Sweeney, J.A. (2002). Neocortical system abnormalities in autism: An fMRI study of spatial working memory. Neurology, 59, 834-840.

Makris, N., Worth, A.J., Sorensen, A.G., Papadimitriou, G.M., Wu, O., Reese, T.G., Wedeen, V.J., Davis, T.L., Stakes, J.W., Caviness, V.S., Kaplan, E., Rosen, B.R., Pandya, D.N., \& Kennedy,
D.N. (1997). Morphometry of in vivo human white matter association pathways with diffusion-weighted magnetic resonance imaging. Annals of Neurology, 42, 951-962.

Mason, R.A., Williams, D.L., Kana, R.K., Minshew, N., \& Just, M.A. (2008). Theory of Mind disruption and recruitment of the right hemisphere during narrative comprehension in autism. Neuropsychologia, 46, 269-280.

McPartland, J., Dawson, G., Webb, S.J., Panagiotides, H., \& Carver, L.J. (2004). Event-related brain potentials reveal anomalies in temporal processing of faces in autism spectrum disorder. Journal of Child Psychology and Psychiatry, 45, 1235-1245.

Minshew, N.J. (1996). Brief report: Brain mechanisms in autism: Functional and structural abnormalities. Journal of Autism and Developmental Disorders, 26, 205-209.

Minshew, N.J. \& Williams, D.L. (2007). The new neurobiology of autism: Cortex, connectivity, and neuronal organization. Archives of Neurology, 64, 945-950.

Mori, S., Crain, B.J., Chacko, V.P., \& van Zijl, P.C. (1999). Threedimensional tracking of axonal projections in the brain by magnetic resonance imaging. Annals of Neurology, 45, 265-269.

Munson, J., Dawson, G., Abbott, R., Faja, S., Webb, S.J., Friedman, S.D., Shaw, D., Artru, A., \& Dager, S.R. (2006). Amygdalar volume and behavioral development in autism. Archives of General Psychiatry, 63, 686-693.

Nacewicz, B.M., Dalton, K.M., Johnstone, T., Long, M.T., McAuliff, E.M., Oakes, T.R., Alexander, A.L., \& Davidson, R.J. (2006). Amygdala volume and nonverbal social impairment in adolescent and adult males with autism. Archives of General Psychiatry, 63, 1417-1428.

Nicolson, R., DeVito, T.J., Vidal, C.N., Sui, Y., Hayashi, K.M., Drost, D.J., Williamson, P.C., Rajakumar, N., Toga, A.W., \& Thompson, P.M. (2006). Detection and mapping of hippocampal abnormalities in autism. Psychiatry Research, 148, 11-21.

Palmen, S.J., Durston, S., Nederveen, H., \& Van Engeland, H. (2006). No evidence for preferential involvement of medial temporal lobe structures in high-functioning autism. Psychological Medicine, 36, 827-834.

Pierce, K., Haist, F., Sedaghat, F., \& Courchesne, E. (2004). The brain response to personally familiar faces in autism: Findings of fusiform activity and beyond. Brain, 127, 2703-2716.

Pierce, K., Muller, R.A., Ambrose, J., Allen, G., \& Courchesne, E. (2001). Face processing occurs outside the fusiform 'face area' in autism: Evidence from functional MRI. Brain, 124, 2059-2073.

Pierpaoli, C., Jezzard, P., Basser, P.J., Barnett, A., \& Di Chiro, G. (1996). Diffusion tensor MR imaging of the human brain. Radiology, 201, 637-648.

Piven, J., Bailey, J., Ranson, B.J., \& Arndt, S. (1998). No difference in hippocampus volume detected on magnetic resonance imaging in autistic individuals. Journal of Autism and Developmental Disorders, 28, 105-110.

Reitan, R.M. \& Wolfson, D. (1993). The Halstead-Reitan Neuropsychological Test Battery: Theory and Clinical Interpretation (2nd ed.). South Tucson, AZ: Neuropsychology Press.

Rump, K.M., Giovannelli, J.L., Minshew, N.J., \& Strauss, M.S. (2008). The development of emotion recognition in individuals with autism. Child Development, (in press).

Rutkove, S.B. (2001). Effects of temperature on neuromuscular electrophysiology. Muscle Nerve, 24, 867-882.

Schultz, R.T. (2005). Developmental deficits in social perception in autism: The role of the amygdala and fusiform face area. International Journal of Developmental Neuroscience, 23, $125-141$ 
Schultz, R.T., Gauthier, I., Klin, A., Fulbright, R.K., Anderson, A.W., Volkmar, F., Skudlarski, P., Lacadie, C., Cohen, D.J., \& Gore, J.C. (2000). Abnormal ventral temporal cortical activity during face discrimination among individuals with autism and Asperger syndrome. Archives of General Psychiatry, 57, 331-340.

Schumann, C.M. \& Amaral, D.G. (2006). Stereological analysis of amygdala neuron number in autism. The Journal of Neuroscience, 26, 7674-7679.

Schumann, C.M., Hamstra, J., Goodlin-Jones, B.L., Lotspeich, L.J., Kwon, H., Buonocore, M.H., Lammers, C.R., Reiss, A.L., \& Amaral, D.G. (2004). The amygdala is enlarged in children but not adolescents with autism; the hippocampus is enlarged at all ages. The Journal of Neuroscience, 24, 6392-6401.

Shimony, J.S., McKinstry, R.C., Akbudak, E., Aronovitz, J.A., Snyder, A.Z., Lori, N.F., Cull, T.S., \& Conturo, T.E. (1999). Quantitative diffusion-tensor anisotropy brain MR imaging: Normative human data and anatomic analysis. Radiology, 212, 770-784.

Smith, C.D., Lori, N., Akbudak, E., \& Conturo, T.E. (2005, May 15-21). Laterality of the amygdalo-fusiform pathway in humans assessed using diffusion tensor tracking (p. 624). Proceedings of the ISMRM. Miami, Florida.

Smith, C.D., Lori, N., Akbudak, E., Sorar, E., Gultepe, E., Shimony, J., McKinstry, R.C., \& Conturo, T.E. (2008). MRI diffusion tensor tracking of a new amygdalo-fusiform and hippocampo-fusiform pathway system in humans. Journal of Magnetic Resonance Imaging (submitted).

Smith, C.D., Lori, N.F., Akbudak, E., Sorar, E., Shimony, J.S., \& Conturo, T.E. (2003). A human amygdalo-fusiform pathway. Annals of Neurology, 54, S76-S77.
Sparks, B.F., Friedman, S.D., Shaw, D.W., Aylward, E.H., Echelard, D., Artru, A.A., Maravilla, K.R., Giedd, J.N., Munson, J., Dawson, G., \& Dager, S.R. (2002). Brain structural abnormalities in young children with autism spectrum disorder. $\mathrm{Neu}$ rology, 59, 184-192.

Stanisz, G.J., Szafer, A., Wright, G.A., \& Henkelman, R.M. (1997). An analytical model of restricted diffusion in bovine optic nerve. Magnetic Resonance in Medicine, 37, 103-111.

Tardif, C., Laine, F., Rodriguez, M., \& Gepner, B. (2007). Slowing down presentation of facial movements and vocal sounds enhances facial expression recognition and induces facialvocal imitation in children with autism. Journal of Autism and Developmental Disorders, 37, 1469-1484.

Tasaki, I. \& Fujita, M. (1948). Action currents of single nerve fibers as modified by temperature changes. Journal of Neurophysiology, 11, 311-315.

Titmus, M.J. \& Faber, D.S. (1990). Axotomy-induced alterations in the electrophysiological characteristics of neurons. Progress in Neurobiology, 35, 1-51.

Townsend, J., Harris, N.S., \& Courchesne, E. (1996). Visual attention abnormalities in autism: Delayed orienting to location. Journal of the International Neuropsychological Society, 2, 541-550.

Wang, A.T., Dapretto, M., Hariri, A.R., Sigman, M., \& Bookheimer, S.Y. (2004). Neural correlates of facial affect processing in children and adolescents with autism spectrum disorder. Journal of the American Academy of Child and Adolescent Psychiatry, 43, 481-490.

Wechsler, D. (1999). Wechsler Abbreviated Scale of Intelligence (WASI). San Antonio, TX: The Psychological Corporation. 